upper respiratory tract infections, 2 urinary tract infection, 1 Herpes labialis), while 3 patients manifested Herpes Zoster reactivation, 2 deep vein thrombosis (one with pulmonary embolism), 2 discontinued due to severe anemia and pancytopenia, and 2 developed self-limiting liver enzymes elevation.

Conclusion: In our real-world dataset, baricitinib is effective in reducing RA disease activity, after 12 weeks, being generally well-tolerated with few severe adverse events.

Disclosure of Interests: Giacomo Maria Guidelli: None declared, Elena Generali: None declared, Chiara Bazzani: None declared, Roberto Gorla: None declared, Garifallia Sakellariou: None declared, Massimiliano Limonta: None declared, Maria Sole Chimenti: None declared, Roberto Perricone: None declared, Edoardo Conticini: None declared, Bruno Frediani: None declared, nicola boffini: None declared, Lorenzo Dagna Consultant for: Prof Lorenzo Dagna received consultation honoraria from Abbvie, Amgen, Biogen, Bristol-Myers Squibb, Celltrion, Novartis, Pfizer, Sanofi-Genzyme, and SOBI., Marta Riva: None declared, Maria Rosa Pozzi: None declared, Rosa Daniela Grembiale Grant/research support from: BMS, Consultant for: JANSSEN, CELGENE, Speakers bureau: PFIZER, JANSSEN, BMS, NOVARTIS, Teodora Serban: None declared, Gerolamo Bianchi Consultant for: Alfa-Sigma, Amgen, BMS, Celgene, Medac, UCB, Speakers bureau: Abbvie, Abiogen, Alfa-Sigma, Amgen, BMS, Celgene, Carlo Selmi Grant/research support from: Abbvie, Janssen, MSD, Novartis, Pfizer, Consultant for: Abbvie, Alfa-Sigma, Biogen, BMS, Celgene, Eli-Lilly, GSK, Janssen, Merck Sharp and Dohme, Novartis, Pfizer, Roche, Sanofi-Genzyme, YCB, Speakers bureau: Abbvie, AlfaSigma, Biogen, BMS, Celgene, Eli-Lilly, GSK, Janssen, Merck Sharp and Dohme, Novartis, Pfizer, Roche, Sanofi-Genzyme, YCB

DOI: 10.1136/annrheumdis-2019-eular.7681

\section{AB0447 $\quad$ BIOLOGICAL THERAPY AND RADIOSYNOVIORTHESIS IN PATIENTS WITH RHEUMATOID ARTHRITIS AND PSORIATIC ARTHRITIS}

Margit Szentesi ${ }^{1}$, Zoltán Nagy ${ }^{2}$, Zsolt Karoly Mangel ${ }^{1}$, Pál Géher ${ }^{1} .{ }^{1}$ Polyclinic of the Hospitaller Brothers of St. John of God, Rheumatology, Budapest, Hungary;

${ }^{2}$ Polyclinic of the Hospitaller Brothers of St. John of God, Budapest, Hungary

Background: The treatment of patients with rheumatoid arthritis (RA) has been spectaculary changed since the 1950's. Introduction of the steroid compounds and their local application, the chemical and radionuclide synovectomy, surgical synovectomy, use of non steroid drugs, the basic treatment and the spread of biological therapy are the most important steps. Introduction of the biological therapy has changed the quality of life for these patients.

Objectives: During biological therapy sometimes 1 or 2 joints could be affected by inflammation. In this cases always the question is how to solve the problem. Change of the biological or basic therapy, use surgical synovectomy or radiosynovectomy (RSO)?

Methods: In our rheumatological department 2100 patients with RA and PA were treated with biological therapy between 2002 and 2015. In 100 patients we applied RSO because of the inflammation of the knee joint during biological therapy. We made a long term follow-up in 72 patients. All participants provided written informed consent.

62 participants inflammatory knee joint disease was diagnosed on the basis of the American College of Rheumatology. 55 of 62 patients with rheumatoid arthritis were seropositive, 7 seronegative. Steinbrocker functional stadium II was observed in 52, stadium III in 10.10 patients were psoriatic arthritis. Mean age of 13 male and 61 female patients was 51.4 years (range 24-79) years. In 38 patients the right knee, in 34 the left knee was treated by radiosynovectomy. Mean duration of disease was 7.3 years (range 0.5-25), of synovitis (6.3month (range 3-8) Mean number of punctions of the treated joint prior to radiosynovectomy was 4,2 per patient and of steroid administrations prior to radiosynovectomy 3,0. In 12 patients a systemic steroid therapy has been performed.

Results: During the study period, inflammation decreased. In the first two years excellent and good results were recorded in $82,2 \%$. Two years after radiosynoviorthesis $83.3 \%$ of patients did not need another punction. Before the knee inflammation patients were in complete remission which status has been achieved after RSO as well. DAS: 2,4+-0,4.

Conclusion:

1. RSO is an effective method to treat the inflammation of the knees.

2. The RSO performed during biological tehrapy is as effective as in the case of patients without biological therapy.

3. In case of a succesful RSO there is no need for biological or basic therapy neither for surgical synovectomy.
4. However an intraarticular injection has a low risk for infection it is recommended to avoid the biological therapy during the RSO.

\section{REFERENCES}

[1] Szekanecz Z.: Célzott terápia a reumatológiában. Klinikum és Tudomány, MOTESZ Magazin; 2010;XVIII(2):31-44.

[2] Mclnnes IB, Schett G. Cytokines in the pathogenesis of rheumatoid arthritis. Nat Rev Immunol. 2007 Jun;7(6):429-42

[3] Klippel JH. Primer on the Rheumatic Disease. 12th ed. 2001

[4] Lipsky PE. Harrison's Principles of Internal Medicine. 16th ed. 2005

[5] EULAR recommendations for the management of rheumatoid arthritis with synthetic and biological disease-modifying antirheumatic drugs: 2013 update

[6] Fellinger K. and Schmid J.: Die lokale Behandlung der rheumatischen Erkrankungen. Z. Inn. Med. 33. 351. 1952.

[7] Stucki G., Bozzone P., Treuer E., Wassmer P. and Felder M.: Efficacy and safety of radiation synovectomy with Yttrium-90: A retrospective long term analysis of 164 applications in 82 patients. British J. of Rheumatology 32 5. 383-386. 1993.

[8] Combe B., Krause E. and Sany J.: Treatment of chronic knee synovitis with arthroscopic synovectomy after failure of intra-articular injection of radionuclide. Arthritis Rheum. 32. 1. 10-14. 1989.

[9] Feldmann M, Maini RN.:Lasker Clinical Medical Research Award. TNF defined as a therapeutic target for rheumatoid arthritis and other autoimmune diseases. Nat Med. 2003 Oct;9(10):1245-50.

Disclosure of Interests: None declared

DOI: 10.1136/annrheumdis-2019-eular.3071

\section{AB0448 1 SAFETY AND EFFICACY OF FILGOTINIB IN JAPANESE PATIENTS ENROLLED IN A GLOBAL PHASE 3 TRIAL OF PATIENTS WITH ACTIVE RHEUMATOID ARTHRITIS AND INADEQUATE RESPONSE OR INTOLERANCE TO BIOLOGIC DMARDS}

Tsutomu Takeuchi ${ }^{1}$, Tsukasa Matsubara ${ }^{2}$, Tatsuya Atsumi ${ }^{3}$, Koichi Amano ${ }^{4}$ Naoki Ishiguro ${ }^{5}$, Eiji Sugiyama ${ }^{6}$, Kunihiro Yamaoka ${ }^{7}$, Mark C. Genovese ${ }^{8}$, Kenneth Kalunian $^{9}$, David Walker ${ }^{10}$, Jacques-Eric Gottenberg ${ }^{11}$, Kurt de Vlam ${ }^{12}$ Neelufar Mozaffarian ${ }^{13}$, Beatrix Bartok ${ }^{13}$. Franziska Matzkies ${ }^{13}$, Jie Gao ${ }^{13}$ Ying Guo ${ }^{13}$, Chantal Tasset ${ }^{14}$, John Sundy ${ }^{13}$, Yoshiya Tanaka ${ }^{15} .{ }^{1}$ Keio University School of Medicine, Tokyo, Japan; ${ }^{2}$ Matsubara Mayflower Hospital, Katō, Japan;

${ }^{3}$ Hokkaido University, Sapporo, Japan; ${ }^{4}$ Saitama Medical Center, Kawagoe, Japan; ${ }^{5}$ Nagoya University, Nagoya, Japan; ${ }^{6}$ Hiroshima University, Hiroshima, Japan; ${ }^{7}$ Kitasato University School of Medicine, Sagamihara, Japan; ${ }^{8}$ Stanford University Medical Center, Stanford, United States of America; ${ }^{9}$ University of California, San Diego, La Jolla, United States of America: ${ }^{10}$ Northumbria Healthcare, Newcastle upon Tyne, United Kingdom; ${ }^{11}$ Strasbourg University Hospital, Strasbourg, France; ${ }^{12}$ Universitair Ziekenhuis Leuven, Leuven, Belgium;

${ }^{13}$ Gilead Sciences, Inc., Foster City, United States of America; ${ }^{14}$ Galápagos NV, Mechelen, Belgium; ${ }^{15}$ University of Occupational and Environmental Health, Kitakyushu, Japan

Background: Filgotinib (FIL), an oral, selective inhibitor of Janus kinase 1 (JAK1), has demonstrated efficacy in a phase 3 study in bDMARD-IR patients with active rheumatoid arthritis (RA)

Objectives: We report results of Japanese patients enrolled in the FINCH2 study (ClinicalTrials.gov Identifier: NCT02873936) of FIL in patients with RA and an inadequate response or intolerance to $\geq 1$ bDMARDs.

Methods: FINCH2 (ClinicalTrials.gov: NCT02873936) was a 24-week randomized, placebo-controlled, phase 3 trial conducted globally at 114 sites, including at sites in Japan, from July 2016-June 2018. Male and female adults with moderately-to-severely active RA and inadequate response/intolerance to $\geq 1$ prior bDMARDs were randomized 1:1:1 to oral doses of FIL $200 \mathrm{mg}$, FIL $100 \mathrm{mg}$, or placebo (PBO) once daily (QD) for 24 weeks; patients continued background therapy with conventional synthetic DMARDs.

Results: Primary and all key secondary endpoints were met for both global ( $N=448$, Genovese, 2018) and Japanese patient populations ( $n=40$ FIL $200 \mathrm{mg}, \mathrm{n}=12$; FIL $100 \mathrm{mg}, \mathrm{n}=15$; and PBO, $\mathrm{n}=13$ ). ACR20 response rates, HAQ-DI LS mean changes from baseline, and the percentage of Japanese patients with DAS28(CRP) $\leq 3.2$ at week 12 are shown in Table 1. In Japanese patients, treatment-emergent adverse event (AE) rates were similar for FIL $200 \mathrm{mg}$, FIL $100 \mathrm{mg}$, and PBO (75\%, $60 \%$, and $77 \%$, respectively) and there were no serious AEs; there was 1 case of uncomplicated herpes zoster (FIL $200 \mathrm{mg}$ ); and no 